\title{
Levels of renalase and advanced oxidation protein products with regard to catecholamines in haemodialysed patients
}

\author{
Marcin Dziedzic ${ }^{1}$, Ewelina Orłowska², Beata Petkowicz³ , Anna Bednarek-Skublewska², \\ Janusz Solski', Małgorzata Goździewska ${ }^{4}$ \\ ${ }^{1}$ Department of Laboratory Diagnostic, Medical University of Lublin, Poland \\ ${ }^{2}$ Department of Nephrology, Medical University of Lublin, Poland \\ ${ }^{3}$ Department of Oral Medicine, Medical University of Lublin, Poland \\ ${ }^{4}$ Institute of Rural Health, Lublin, Poland
}

Dziedzic M, Orłowska E, Petkowicz B, Bednarek-Skublewska A, Solski J, Goździewska M. Levels of renalase and advanced oxidation protein products with regard to catecholamines in haemodialysed patients. Ann Agri Environ Med. 2017; 24(3): 453-458. doi: 10.5604/12321966.1233567

\begin{abstract}
Introduction. The main mediators of the sympathetic nervous system in the effectors part are catecholamines (CA). An increased sympathetic nerve activity observed in chronic kidney disease (CKD), is due to a raised level of CA in plasma. Renalase is a protein secreted by the kidneys, composed of 342 amino acids, which is able to metabolize the circulating CA and possibly play an important role in the regulation of sympathetic tone and blood pressure. Also, oxidative stress, defined as a disruption of the equilibrium between the generation of oxidants, is a crucial factor in the development of the inflammatory syndrome associated with CKD. The advanced oxidation protein products (AOPP) represent exquisite markers of phagocyte-derived oxidative stress.

Objective. The aim of the study was to investigate the concentration of renalase and explore the associations between AOPP with regards to CA in haemodialysis (HD) patients.

Materials and method. The study was conducted among 50 residents of the municipality and neighbouring villages in the province of Lublin, central-eastern Poland.

Results. In the studied patients, it was found that an average concentration of renalase was $44.8 \pm 6.5 \mu \mathrm{g} / \mathrm{mL}$, whereas of AOPP plasma levels $-57.5 \pm 21.5 \mu \mathrm{mol} / \mathrm{L}$. The results demonstrated the correlation between levels of renalase and AOPP in the HD patients. Indeed, elevated levels of renalase and AOPP in HD may be due to the presence of uremic toxins in blood. The concentration of urea affects the plasma concentrations of AOPP and renalase causing a direct relationship between renalase and AOPP. However, there is no clear relationship between renalase and circulating catecholamines in HD patients.
\end{abstract}

\section{Key words}

renalase, advanced oxidation protein products, catecholamines, haemodialysis

\section{INTRODUCTION}

The main mediators of the sympathetic nervous system in the effectors part are catecholamines (CA): noradrenaline (NA), adrenaline (A) and dopamine (DA). Neurotransmitters are biogenic amines derived from the amino acid tyrosine and possess a catechol group with an attached amine group $[1,2]$. The described mediators are synthesized both in the brain and in peripheral organs and cells, such as the adrenal medulla, non-neuronal gut cells, platelets and lymphocytes [2]. CA are able to influence many biological processes and are closely related to blood pressure (BP) regulation.

An increased sympathetic nerve activity observed in chronic kidney disease (CKD), is due to the raised CA levels in plasma, resulting from the inhibition of nitric oxide, followed by an increased angiotensin II level and the absence of renalase, as well as a reduced CA clearance in the kidneys. CKD may include a variety of metabolic dysfunctions, among them the accumulation of uraemic toxic substances, leading to neurological disorders particularly related to sympathetic dysfunctions.

Addres for correspondence: Marcin Dziedzic, Department of Laboratory Diagnostic, Medical University of Lublin, Poland

E+mail: marcin8303@interia.eu

Receivd; 27 Jule 2015; accepted: 28 June 2016; first published: February 2017
Renalase is a protein composed of 342 amino acids. Recently discovered as a new renal hormone, renalase - flavin adenine dinucleotide (FAD) - dependent amine oxidase $[3,4,5]$, is secreted by the kidneys and can metabolize the circulating $\mathrm{CA}$ and possibly play an important role in the regulation of sympathetic tone and blood pressure. The concept that renalase might be involved in the regulation of blood pressure is supported by the fact that the inactivation of the RNLS gene in mice by homologous recombination is associated with an elevated blood pressure, and a sympathetic activity in the absence of other measurable changes in renal function $[6,7$, $8]$. The relationship between renalase and catecholamines has been intensively studied since their discovery. However, the possible role of renalase in the pathogenesis of hypertension in haemodialysis (HD) patients is still not fully understand

Oxidative stress, defined as a disruption of the equilibrium between the generation of oxidants and the activity of antioxidant systems, plays a significant role in the development of the inflammatory syndrome associated with CKD and hemodialysis [9]. The advanced oxidation protein products (AOPP) represent exquisite markers of phagocytederived oxidative stress, and their role in the pathophysiology of CKD and dialysis-related complications might be of great importance. The significance of AOPP has been analysed in numerous diseases as they are widely regarded as easily 
measurable markers of oxidative stress. Moreover, the AOPP accumulation is an independent risk factor for cardiovascular events (CVDs) in CKD. Only in HD patients, the AOPP levels exhibit an association with ischaemic heart disease. Thus, there is a need for simple and cheap biomarkers to assess the oxidative stress levels in these patients. Furthermore, the mechanism of accumulation of AOPP, which is affected by the dialysis modality, remains unclear.

It is worth pointing out that patients with advanced chronic kidney disease under hemodialysis treatment have a high prevalence of protein-energy malnutrition and inflammation. As these three conditions often occur concomitantly in HD patients, they have been referred together as 'Malnutrition-Inflammation-Atherosclerosis' (MIA) syndrome to emphasize its important association with atherosclerotic cardiovascular disease. Possible causes of MIA syndrome include comorbid illnesses, oxidative and carbonyl stress, nutrient loss through dialysis, anorexia and low nutrient intake, uremic toxins, decreased clearance of inflammatory cytokines, volume overload, and dialysisrelated factors. MIA syndrome is believed to be the main cause of erythropoietin hyporesponsiveness, high rate of cardiovascular atherosclerotic disease, decreased quality of life, and increased mortality and hospitalization in dialysis patients. Regarding atherosclerosis, the kidney can be victim or villain. On the one hand, both kidney disease per se and renal insufficiency can induce vascular damage, thereby increasing cardiovascular risk. Moreover, the kidney can be the victim of atherosclerosis. Ischemic nephropathy, caused by atherosclerotic renal artery disease and atheroembolism from the abdominal aorta, are two examples. Finally, it is important to consider that the kidney, being an organ with a wide vasculature, could be a sophisticated sensor of subclinical cardiovascular damage.

Therefore, there are many mechanisms underpinning the increased cardiovascular disorders. Recent studies have explored association between variants in the renalase gene and an increased risk of cardiovascular disorders [10]. Renalase gene RNLS resides on chromosome 10 (10q23.31). Stec et al. [11] investigate the association between rs10887800 and rs2576178 renalase gene polymorphisms and risk of coronary artery disease (CAD) in HD patients. The authors [11] observed that rs10887800 renalase gene polymorphism significantly increased the risk of CAD in HD. Moreover, the rs10887800 polymorphism affected the CAD risk independently of age, gender and other CAD risk factors, including smoking, BMI, hyperlipidemia, arterial hypertension and diabetes mellitus. Besides, Buraczyńska et al. [10] demonstrate that renalase gene polymorphism rs2296545 is associated with hypertension in type 2 diabetes patients. Also, authors reported a strong association of the rs10887800 polymorphism with stroke in diabetes patients with hypertension, and also in stroke patients without diabetes.

The aim of the study was to investigate the renalase concentration and explore the associations between AOPP with regards to CA in haemodialysis patients. The effects of hemodialysis sessions on CA levels were also assessed.

\section{MATERIALS AND METHODS}

The study was conducted among residents of the municipality and neighbouring villages in the province of Lublin, centraleastern Poland. Fifty subjects (25 males and 25 females) on haemodialysis, aged $68.5 \pm 16.1$ years, median time on HD: 45.5 months, were investigated.

The study protocol was approved by the local Ethics Committee at the Medical University in Lublin. All patients qualified to participate in the study were informed about the aim and were asked to sign a written consent.

All patients underwent a clinical examination in the Department of Nephrology of the Medical University in Lublin. All observed subjects underwent HD 3 times a week. Each procedure lasted from 3.5-4.5 hours. Lowflux dialyzers were used; bicarbonate dialysate contained a calcium concentration of $1.5 \mathrm{mmol} / \mathrm{ml}$. A dialyzer blood flow rate ranged between $230-400 \mathrm{ml} / \mathrm{min}$, while the dialysate flow rate was $500 \mathrm{ml} / \mathrm{min}$.

Blood samples were obtained from the venous part of the vascular access prior to HD. Standard phlebotomy techniques were used to obtain the samples. The blood samples were later stored in chilled tubes (EDTA) at $4^{\circ} \mathrm{C}$. Plasma was then separated and stored at $-80^{\circ} \mathrm{C}$ until analysis. The concentration of AOPP and renalase were measured prior to HD from the plasma. Similarly, the haematological testing was carried out using the collected blood. Also, several scores and parameters were calculated for each patient, such as comorbidity score (CS) according to the scale published by Charlson et al. [12]. HD adequacy was expressed by Kt/V parameter [13], normalized protein catabolic rate [14], body mass index (BMI), and mean arterial pressure (MAP). MAP was calculated on the basis of blood pressure measurement taken prior to $\mathrm{HD}$ in a horizontal position. The following formula was used: MAP $=$ diastolic pressure $+1 / 3$ (systolic pressure-diastolic pressure). The well-controlled blood pressure was assessed according to KDIGO guidelines as lower then 140/90 $\mathrm{mmHg}$ in $\mathrm{HD}$ patients before haemodialysis session, and lower than 130/80 $\mathrm{mmHg}$ after the session [15]. The following biochemical parameters were measured using an enzyme-linked immunosorbent assay (ELISA): AOPP (R\&D Systems Inc.) and renalase (USCN Life Science, Inc.) assays (sensitivity; the minimum detectable dose less than $0.57 \mathrm{ng} / \mathrm{mL}$ ). The analysis of CA levels in biological fluids has necessitated the use of highly sensitive analytical techniques. Therefore, the extraction of catecholamines from plasma was carried out with a ChromSystems Reagent kit for HPLC analysis. Plasma concentration of catecholamines was measured prior to and following haemodialysis by the method of high performance liquid chromatography with electrochemical detection (HPLC-ED), limit of quantification: NA 15 ng/L, A 15 ng/L, DA 30 ng/L.

Statistical analysis. All values were expressed as mean and standard deviations. Distributions of the analyzed variables were tested using the Shapiro-Wilk test. For normally distributed variables, comparison of the obtained results was analyzed by the Student t-test. For variables that did not demonstrate any compliance with the normal distribution, the non-parametric U Mann-Whitney test was applied. Statistical relationship between the 2 variables was investigated using Spearman's test for correlation. In all tests, $\mathrm{p}$-value $<0.05$ was considered as statistically significant 
for differences or correlations. All statistical analyses were conducted using Statistica 10.0 software.

\section{RESULTS}

The main demographic and clinical characteristics of the patients included in the study are listed in the Table 1. As a result of the conducted study, it was found that the concentration of renalase was $44.8 \pm 6.5 \mu \mathrm{g} / \mathrm{mL}$, whereas the plasma levels of advanced oxidation protein products were $57.5 \pm 21.5 \mu \mathrm{mol} / \mathrm{L}$. After taking into consideration the patients gender, no significant differences were found in the plasma concentration of renalase or AOPP ( $p>0.05)$. $\mathrm{CA}$ concentration before and after HD treatment are presented in Table 1. The results indicated that NA before $\mathrm{HD}(633.4 \pm 333.0 \mathrm{pg} / \mathrm{mL})$ in plasma had a significantly lower concentration after haemodialysis treatment $(451.0 \pm 249.8$ at $\mathrm{p}<0,001)$. Univariate correlations of circulating renalase and AOPP concentrations are presented in Tables 2 and 3. According to the correlation analysis, plasma levels of renalase were directly proportional to the concentration of

Table 1. Demographic and biochemical characteristics of patients on long-term dialysis

\begin{tabular}{|c|c|c|c|}
\hline Parameter & $\begin{array}{c}\text { Whole } \\
\text { study group } \\
\text { Mean } \pm \\
\text { Standard } \\
\text { deviation } \\
\mathrm{N}=50\end{array}$ & $\begin{array}{c}\text { Mean } \pm \\
\text { Standard } \\
\text { deviation } \\
\mathrm{N}=25\end{array}$ & $\begin{array}{c}\text { Mean } \pm \\
\text { Standard } \\
\text { deviation } \\
\mathrm{N}=25\end{array}$ \\
\hline Age [years] & $68.6 \pm 16.2$ & $73.1 \pm 12.8^{*}$ & $63.8 \pm 18.1$ \\
\hline Time on HD [months] & $48.0 \pm 34.6$ & $45.72 \pm 36.7$ & $50.4 \pm 32.9$ \\
\hline $\mathrm{BMI}\left[\mathrm{kg} / \mathrm{m}^{2}\right]$ & $26.7 \pm 6.6$ & $25.4 \pm 3.7$ & $28.0 \pm 8.5$ \\
\hline $\mathrm{Kt} / \mathrm{V}$ & $1.6 \pm 0.2$ & $1.5 \pm 0.2 *$ & $1.6 \pm 0.3$ \\
\hline Haemoglobin $[\mathrm{g} / \mathrm{dL}]$ & $10.4 \pm 1.1$ & $10.6 \pm 1.0$ & $10.3 \pm 1.2$ \\
\hline Ferritin $[\mathrm{ng} / \mathrm{mL}]$ & $258.4 \pm 177.8$ & $224.8 \pm 156.5$ & $281.5 \pm 192.6$ \\
\hline EPO dose $[\mathrm{U} / \mathrm{kg}]$ & $66.9 \pm 37.3$ & $62.4 \pm 38.6$ & $71.0 \pm 36.5$ \\
\hline $\operatorname{CRP}[\mu \mathrm{g} / \mathrm{mL}]$ & $6.9 \pm 4.7$ & $8.72 \pm 4.4 *$ & $5.3 \pm 4.5$ \\
\hline Total Calcium $[\mathrm{mmol} / \mathrm{L}]$ & $2.2 \pm 0.2$ & $2.1 \pm 0.1$ & $2.2 \pm 0.2$ \\
\hline Phosphorus [mg/dL] & $1.6 \pm 0.4$ & $1.5 \pm 0.4$ & $1.7 \pm 0.5$ \\
\hline PTH [pg/mL] & $632.9 \pm 510.3$ & $478.9 \pm 208.5$ & $738.8 \pm 627.0$ \\
\hline Urea $[\mathrm{mg} / \mathrm{dL}]$ Before HD & $110.2 \pm 25.5$ & $113.2 \pm 23.2$ & $107.1 \pm 27.8$ \\
\hline Urea [mg/dL] After HD & $29.6 \pm 8.4$ & $31.8 \pm 7.0$ & $27.3 \pm 9.3$ \\
\hline Comorbidity Score & $7.0 \pm 2.9$ & $7.4 \pm 2.5$ & $6.5 \pm 3.2$ \\
\hline Renalase $[\mu \mathrm{g} / \mathrm{mL}]$ & $44.8 \pm 6.5$ & $43.5 \pm 7.2$ & $46.2 \pm 5.5$ \\
\hline Noradrenaline $[\mathrm{pg} / \mathrm{mL}]$ Before HD & $\begin{array}{l}633.4 \pm \\
333.0 \dagger\end{array}$ & $\begin{array}{l}708.8 \pm \\
326.1 *\end{array}$ & $551.5 \pm 327.7$ \\
\hline Adrenaline $[\mathrm{pg} / \mathrm{mL}]$ Before HD & $71.5 \pm 63.9 \dagger$ & $66.1 \pm 52.3$ & $77.4 \pm 75.3$ \\
\hline Dopamine $[\mathrm{pg} / \mathrm{mL}]$ Before HD & $13.7 \pm 7.9$ & $14.1 \pm 8.9$ & $13.3 \pm 7.0$ \\
\hline Noradrenaline $[\mathrm{pg} / \mathrm{mL}]$ After HD & $451.0 \pm 249.8$ & $485.9 \pm 266.6$ & $416.2 \pm 232.0$ \\
\hline Adrenaline $[\mathrm{pg} / \mathrm{mL}]$ After HD & $49.6 \pm 32.0$ & $53.5 \pm 35.2$ & $45.7 \pm 28.7$ \\
\hline Dopamine $[\mathrm{pg} / \mathrm{mL}]$ After HD & $7.2 \pm 4.8$ & $8.1 \pm 6.0$ & $6.3 \pm 3.0$ \\
\hline AOPP $[\mu \mathrm{mol} / \mathrm{L}]$ & $57.5 \pm 21.5$ & $54.5 \pm 23.4$ & $60.6 \pm 19.4$ \\
\hline Diastolic blood pressure $[\mathrm{mm} / \mathrm{Hg}]$ & $70.9 \pm 13.0$ & $73.4 \pm 12.8$ & $68.3 \pm 13.1$ \\
\hline Systolic blood pressure $[\mathrm{mm} / \mathrm{Hg}]$ & $125.6 \pm 41.8$ & $129.4 \pm 54.2$ & $121.6 \pm 23.6$ \\
\hline $\operatorname{MAP}[\mathrm{mmHg}]$ & $86.9 \pm 12.7$ & $87.7 \pm 11.7$ & $86.0 \pm 13.9$ \\
\hline
\end{tabular}

Table 3. Correlations between advanced oxidation protein products and analyzed parameters

\begin{tabular}{|c|c|c|c|}
\hline Parameter & $\begin{array}{c}\text { Whole } \\
\text { study group } \\
\text { Spearman R }\end{array}$ & $\begin{array}{c}\text { Males } \\
\text { Spearman R }\end{array}$ & $\begin{array}{c}\text { Females } \\
\text { Spearman R }\end{array}$ \\
\hline Age [years] & -0.08 & 0.08 & -0.15 \\
\hline Time on HD [months] & 0.1 & -0.06 & 0.18 \\
\hline Haemoglobin $[\mathrm{g} / \mathrm{dL}]$ & -0.14 & -0.1 & -0.17 \\
\hline Ferritin $[\mathrm{ng} / \mathrm{mL}]$ & -0.17 & 0.06 & -0.32 \\
\hline $\mathrm{CRP}[\mu \mathrm{g} / \mathrm{mL}]$ & -0.01 & $-0.48 * * *$ & $0.41 * * *$ \\
\hline Total Calcium [mmol/L] & -0.11 & -0.1 & -0.09 \\
\hline Phosphorus [mg/dL] & 0.5 * & 0.5 * & $0.45 * *$ \\
\hline PTH $[\mathrm{pg} / \mathrm{mL}]$ & 0.09 & -0.10 & 0.16 \\
\hline Urea [mg/dL] Before HD & 0.22 & $0.51 * *$ & 0.001 \\
\hline Urea [mg/dL] After HD & 0.24 & 0.65 * & 0 \\
\hline Renalase $[\mu \mathrm{g} / \mathrm{mL}]$ & $0.46 *$ & $0.56 *$ & 0.35 \\
\hline Noradrenaline $[\mathrm{pg} / \mathrm{mL}]$ Before HD & 0.09 & 0.27 & 0.04 \\
\hline Adrenaline $[\mathrm{pg} / \mathrm{mL}]$ Before HD & -0.18 & -0.21 & -0.19 \\
\hline Dopamine $[\mathrm{pg} / \mathrm{mL}]$ Before HD & 0.01 & -0.08 & 0.07 \\
\hline Noradrenaline $[\mathrm{pg} / \mathrm{mL}]$ After HD & 0.07 & 0.23 & 0 \\
\hline Adrenaline $[\mathrm{pg} / \mathrm{mL}]$ After HD & 0.05 & $0.45 * *$ & -0.30 \\
\hline Dopamine $[\mathrm{pg} / \mathrm{mL}]$ After HD & 0.25 & 0.27 & 0.29 \\
\hline Diastolic blood pressure $[\mathrm{mm} / \mathrm{Hg}]$ & -0.09 & 0.01 & -0.13 \\
\hline Systolic blood pressure $[\mathrm{mm} / \mathrm{Hg}]$ & -0.06 & 0.02 & -0.14 \\
\hline $\operatorname{MAP}[\mathrm{mmHg}]$ & -0.09 & 0.001 & -0.16 \\
\hline
\end{tabular}

Table 2. Correlations between concentration of renalase $(\mu \mathrm{g} / \mathrm{mL})$ and analyzed parameters

\begin{tabular}{|c|c|c|c|}
\hline Parameter & $\begin{array}{l}\text { Whole study } \\
\text { group } \\
\text { Spearman R }\end{array}$ & $\begin{array}{c}\text { Males } \\
\text { Spearman R }\end{array}$ & $\begin{array}{c}\text { Females } \\
\text { Spearman R }\end{array}$ \\
\hline Age [years] & -0.05 & -0.03 & 0.07 \\
\hline Time on HD [months] & 0.22 & 0.06 & 0.26 \\
\hline Haemoglobin [g/dL] & 0.04 & 0.20 & -0.08 \\
\hline Ferritin [ng/mL] & -0.12 & -0.32 & -0.19 \\
\hline $\mathrm{CRP}[\mu \mathrm{g} / \mathrm{mL}]$ & 0.03 & -0.42 & 0.40 \\
\hline Total Calcium [mmol/L] & -0.07 & -0.06 & -0.08 \\
\hline Phosphorus [mg/dL] & 0.23 & 0.24 & 0.20 \\
\hline PTH $[\mathrm{pg} / \mathrm{mL}]$ & 0.36 & 0.25 & $0.56 * *$ \\
\hline Urea [mg/dL] Before HD & 0.19 & 0.21 & 0.19 \\
\hline Urea [mg/dL] After HD & 0.24 & $0.5 * *$ & 0.17 \\
\hline Noradrenaline $[\mathrm{pg} / \mathrm{mL}$ ] Before HD & 0.19 & 0.18 & 0.37 \\
\hline Adrenaline $[\mathrm{pg} / \mathrm{mL}]$ Before HD & -0.05 & -0.05 & 0.006 \\
\hline Dopamine $[\mathrm{pg} / \mathrm{mL}]$ Before HD & -0.05 & 0.02 & -0.01 \\
\hline Noradrenaline $[\mathrm{pg} / \mathrm{mL}]$ After HD & $0.32 * *$ & $0.45 * *$ & 0.25 \\
\hline Adrenaline $[\mathrm{pg} / \mathrm{mL}]$ After $\mathrm{HD}$ & -0.05 & 0.24 & 0.25 \\
\hline Dopamine [pg/mL] After HD & 0.03 & 0.32 & -0.05 \\
\hline $\mathrm{AOPP}[\mu \mathrm{mol} / \mathrm{L}]$ & $0.46 *$ & $0.56 *$ & 0.35 \\
\hline Diastolic blood pressure $[\mathrm{mm} / \mathrm{Hg}]$ & -0.09 & -0.04 & -0.09 \\
\hline Systolic blood pressure $[\mathrm{mm} / \mathrm{Hg}]$ & -0.13 & -0.25 & 0.01 \\
\hline $\mathrm{MAP}[\mathrm{mmHg}]$ & -0.09 & -0.12 & -0.03 \\
\hline
\end{tabular}

${ }^{*} p<0.05 ; * * p<0.01 ; * * * p<0.001$ 
NA after HD in whole investigated group of patients $(\mathrm{R}=0.32$; $\mathrm{P}<0.001)$ (Fig. 1), and also in the group of men $(\mathrm{R}=0.45$; $\mathrm{P}<0,001)$. Furthermore, renalase levels positively correlated with AOPP in the whole study group $(\mathrm{R}=0.46 ; \mathrm{P}<0.05)($ Fig. 2$)$ and in men $(\mathrm{R}=0.56 ; \mathrm{P}<0.05)$. Moreover, a positive correlation was noted between AOPP and phosphorus levels $(\mathrm{R}=0.5$; $\mathrm{P}<0,001)$ in the whole study group as well as in men $(\mathrm{R}=0.5$; $\mathrm{P}<0.001)$ and in women $(\mathrm{R}=45 ; \mathrm{P}<0.05)$ (Tab. 3$)$. In addition, there was no significant correlation between the levels of renalase and age, duration of dialysis therapy, diastolic blood pressure, systolic blood pressure, MAP, CRP, CA before HD, nor A, DA after HD (Tab. 2). Moreover, no correlation was found between CA and AOPP.

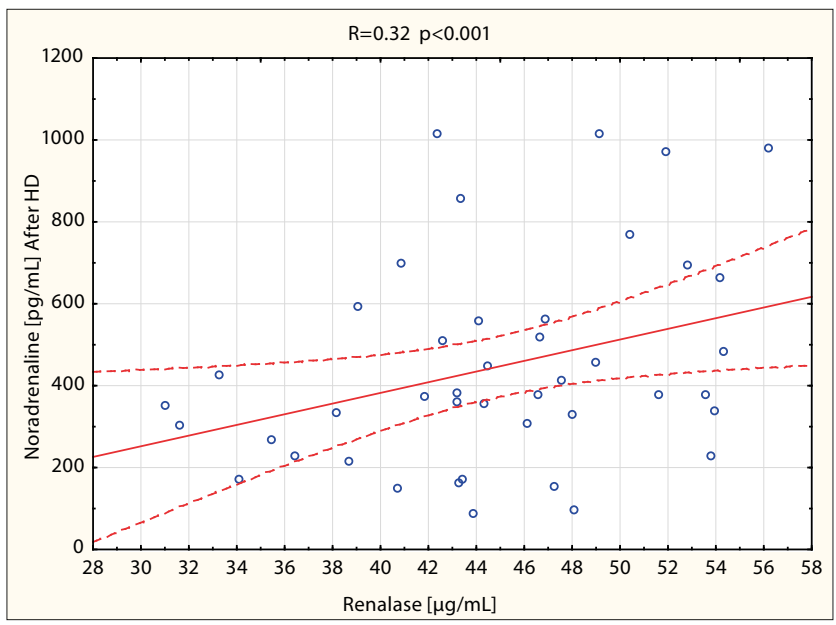

Figure 1. Correlation between levels of renalase and noradrenaline in haemodialysed patients in the whole study group.

solid line - regresion line; dotted lines - 95\% confidence intervals

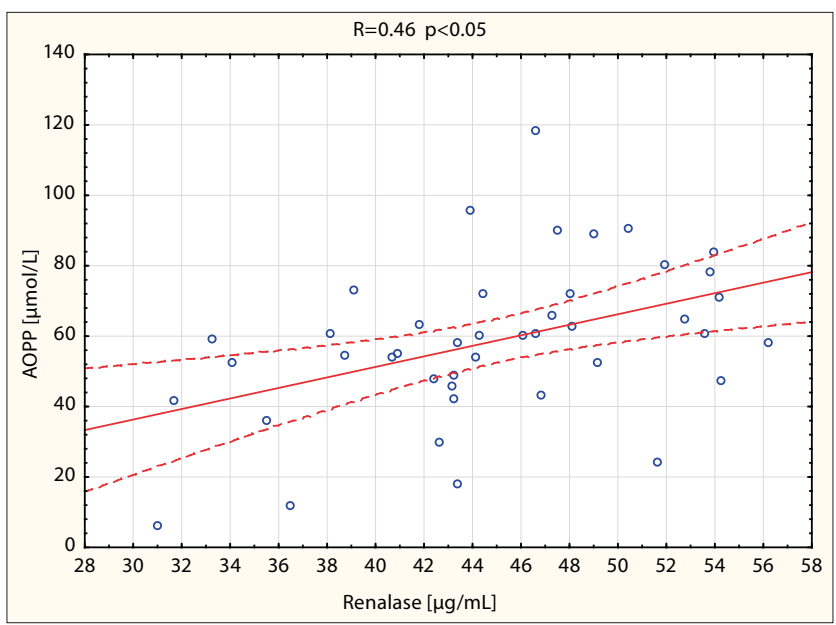

Figure 2. Correlation between levels of renalase and advanced oxidation protein products (AOPP) in the whole study group.

solid line - regresion line; dotted lines - $95 \%$ confidence intervals

\section{DISCUSSION}

Patients with advanced CKD undergoing HD have an increased risk of cardiovascular morbidity and mortality. Endothelial dysfunction is one of the mechanisms that exacerbate atherosclerosis and lead to CVDs. The factors induced in pathogenesis of endothelial dysfunction in haemodialysis patients are still unclear.
The accumulation of AOPP has been recognized in patients with CKD. In the presented study, in HD patients, it was noticed that the plasma concentrations of AOPP were elevated. These results were in agreement with Zadrazil et al. [16] who stated that plasma concentrations of AOPP increased with the progression of CKD and were closely related to the advanced glycation end products (AGEs). In addition, WitkoSarsat et al. [17] provided information on AOPP, claiming that they are able to trigger the synthesis of inflammatory cytokines in neutrophil leukocytes and monocytes, and seem to act as inflammatory mediators in CKD patients. Focusing on the AOPP, it has been recognized that the HD process may lead to a generation of reactive oxygen species, impairing the antioxidant capacity of the organism [18]. However, detailed pathways for oxidative stress in HD patients are still poorly understood. Increased levels of AOPP observed in the presented study can be explained by the fact that the cumulative iron loading used for treatment of anaemia might be a resource of reactive oxygen species. Also, other consequences are coming in line with the presented finding: elevated AOPP concentration may also be affected by high levels of uraemic toxins and disturbances of the calcium-phosphate homeostasis regulation. According to the authors' best knowledge, uraemic toxins, hypothyroidism, hypersplenism and ongoing infection can reduce the erythrocyte life span, contributing to a renal anaemia. Anaemia has been shown to be significantly associated with left ventricular hypertrophy in dialysis patients [19] connected with an endothelial dysfunction, cardiovascular risk and the progression of renal damage.

In the presented study, it was observed that renalase expression correlated with AOPP. Thus, the obtained results may constitute an explanation for the high renalase activity reduced by the inhibition of circulating enzyme in CKD patients. No clear relations between circulating renalase and CA in plasma have been observed. Recently, much research performed on the metabolism of circulating CA has focused on renalase. This recently discovered compound, flavinadenin dinucleotide (FAD) containing hormone, is secreted by the kidneys, circulates in the blood, and may play a key role in the metabolism of CA $[20,21,22]$. However, the role of renalase as a catalyzer of aminochromes production remains unconfirmed.

The current study shows elevated levels of renalase and $\mathrm{CA}$ in $\mathrm{HD}$ patients. In addition, no significant correlations between CA and renalase were observed. These findings are in agreement with the studies by Zbroch and Malyszko [23] who did not observe any correlation between DA, NA and renalase levels. The elevated concentrations of CA in end-stage renal disease (ESRD) patients are the results not only of the inhibition of nitric oxide (NO), followed by an increased angiotensin II level and a rise in sympathetic afferent outflow from the diseased kidney, but also from a reduced CA clearance [24]. Also, the abnormalities in the renalase pathway are discussed in the case of these patients $[25,26]$. Nevertheless, it should be emphasized that renalase is secreted not only by the kidney, but also by cardiomyocytes, liver, adipose tissue, skeletal muscles, endothelium, and by the Central Nervous System [27]. Previously, Gu et al. [28] reported an increased renalase concentration in HD patients. They hypothesized that in this condition a more activated renalase was synthesized to cope with the increased NA levels. Recently, renalase was 
suggested to preferentially metabolize the circulating A, and its capacity to decrease blood pressure is directly correlated to this particular enzymatic activity $[29,30]$. However, to metabolize A, renalase uses a mechanism that is different from that exhibited by the monoamine oxidase (MAO). Indeed, unlike MAOs, renalase uses nicotinamide adenine dinucleotide (NADH) as a cofactor and reacts with oxygen to generate superoxide anion $[31,32]$. This reaction scheme is similar to that of flavoprotein monooxygenases, a diverse class of enzymes that can catalyze a wide variety of oxidation reactions, including amine oxidation. Małyszko et al. [33], reported that renalase is secreted by the kidneys, and to a much lesser extent it is also removed by dialysis. The same authors claimed that is no clear relationship between renalase and blood pressure, at least in patients with CKD, and could not confirm that renalase was a monoamine oxidase, or even an oxidase at all [34]. In contrast to the study by Beaupre et al. [35], who reported that renalase does not consume catecholamines, renalase is not kinetically regulated by CA and renalase is not isolated in an inhibited form and cannot be activated by blood plasma or CA. In addition, Beaupre et al. [35] suggested that blood has very little active renalase. This observation is consistent with its newly-identified activity and suggest that renalase has an exclusively intracellular/ metabolic role. Other authors [36] have also raised serious doubts regarding the putative catecholamine-degrading activity of renalase, suggesting that although renalase may have an important physiological role in the context of hypertension and cardiorenal disease, it appears unlikely to be mediating the degradation of catecholamines. Wang et al. [37] showed that renalase promoted cell survival and protected against renal ischaemia reperfusion injury in mice through the activation of intracellular signalling cascades, independent of its ability to degrade catecholamines. More recently, Moran et al. [38] found that, in fact, renalase does bind to , and performs no catalyic transformation of A [39]. Quelhas-Santos et al. [40] reported that renalase degrades catecholamines catalyzing the formation of aminochromes.

The discrepancy among studies may be related to the methods of determination. The different results in blood levels based on western blots and ELISA need further exploration and raise concerns about the interpretation of renalase levels in patients with kidney disease. The most relevant issue is that the two antibodies used in the commercial sandwich ELISA kit (Uscn Life) have not been fully validated. The identity of the antibodies and the epitopes they recognize, and information on how they behave in native western blots is not available. For example, they may recognize epitopes undetected by the original studies with polyclonal antibodies [41, 42, 43]. Alternatively, increased renalase levels by ELISA in advanced CKD could be due to accumulated renalase breakdown products, or to cross-reaction with an unrelated epitope. The polyclonal antibody predominantly detects the dimeric form of renalase $(\sim 75 \mathrm{kDa})$, with an estimated concentration of 4 $\mu \mathrm{g} / \mathrm{mL}$, while the monoclonal preferentially binds to higher molecular weight species. It is possible that lower GFR could favor the formation and accumulation of higher molecular weight multimers. It is interesting that western blot and ELISA give virtually identical results in subjects with normal renal function. Finally, it is possible that the measurement of plasma renalase activity may be the answer to this issue, as it would provide important insights into the function of renalase in health and disease $[43,44]$. Therefore, recombinant renalase exerts powerful and rapid hypotensive effects on rats through including catecholamines degradation. Yin et al. [45] confirmed the beneficial effects of renalase supplementation on functional and histological alterations of kidney and heart, and investigated the underlying mechanism in a rat model with progressive renal injury. Furthermore, the authors [45] have demonstrated that the systematic delivery of renalase, a kidney-derived protein, attenuated both renal and cardiac fibrosis, improved renal function and prevented cardiac remodeling six weeks after renal ablation through its anti-inflammatory and anti-oxidant effects, inhibition of extracellular signal-regulated kinase (ERK) pathway, which indicate that renalase may play a crucial role in the interaction between kidney and heart. Taken together, these findings indicated renalase supplementation might protect renal injury through inhibiting inflammation activation and oxidative stress in remnant kidney. Taking all these new data into consideration, it seems intriguing that these studies yielded contradictory results. The nature of this interaction needs to be evaluated by further experimental and longitudinal clinical studies to clarify whether there really exists a cause-effect relationship.

\section{CONCLUSIONS}

The results of the presented study demonstrate the correlation between levels of renalase and advanced oxidation protein products in haemodialysis patients. Indeed, the elevated levels of renalase and AOPP in HD may be due to the presence of uraemic toxins. The concentration of urea affects the plasma concentrations of AOPP and renalase, causing a direct relationship between renalase and AOPP. Of note, lowering plasma AOPP concentration may represent therapeutic target for prevention of cardiovascular events in progressive renal damage. Moreover, there is no clear relationship between renalase and circulating catecholamines in HD patients. Regardless of the mechanism underlying their association, it seems important to study the interaction between CA and renalase levels with respect to the high mortality and cardiovascular morbidity rates for patients with ESRD. Prospective studies are needed to better elucidate the role of renalase and AOPP with regard to catecholamines in haemodialysis patients.

\section{REFERENCES}

1. Axelord J, Weinshilboum R. Catecholamines. New Engl J Med. 1972; 2: 237-287.

2. Sarkar C, Chakroborty D, Basu S. Neurotransmitters as regulators of tumor angiogensis and immunity: the role of catecholamines. J Neuroimmune Pharmacol 2012; 10: 11481-11512.

3. Xu J, Li G, Wang P, Velazquez H, Yao X, Li Y, et al. Renalase is a novel, soluble monoamine oxidase that regulates cardiac function and blood pressure. J Clin Invest. 2005; 115(5): 1275-1280.

4. Moran GR. The catalytic function of renalase: A decade of phantoms. Biochim Biophys Acta. 2016; 1864(1): 177-86.

5. Desir GV. Regulation of blood pressure and cardiovascular function by renalase. Kidney Int. 2009; 76(4): 366-70.

6. Wu Y, Xu J, Velazquez H, et al. Renalase deficiency aggravates ischemic myocardial damage. Kidney Int. 2011; 79(8): 853-60.

7. Quelhas-Santos J, Pestana M. Plasma Renalase in Chronic Kidney Disease: Differences and Similarities between Humans and Rats Current Hypertension Reviews. 2014; 10: 166-170. 
8. Salman IM. Cardiovascular Autonomic Dysfunction in Chronic Kidney Disease: a Comprehensive Review. Curr Hypertens Rep. 2015; 17(8): 59

9. Witko-Sarsat V, Gausson V, Descamps-Latscha B. Are advanced oxidation protein products potential uremic toxins? Kidney Int Suppl. 2003; 5(84): 11-4

10. Buraczynska M, Zukowski P, Buraczynska K, Mozul S, Ksiazek A. Renalase gene polymorphisms in patients with type 2 diabetes, hypertension and stroke. Neuromolecular Med. 2011; 13(4): 321-7.

11. Stec A, Ksiazek A, Buraczynska M. Rs10887800 renalase gene polymorphism is associated with an increased risk of coronary artery disease in hemodialyzed patients. Int Urol Nephrol. 2016; 48(6): 871-6.

12. Charlson ME, Pompei P, Ales KL, MacKenzie CR. A new method of classifying prognostic comorbidity in longitudinal studies: development and validation. J Chronic Dis. 1987; 40(5): 373-383.

13. Daugirdas JT. Second generation logarithmic estimates of single-pool variable volume Kt/V: an analysis of error. J Am Soc Nephrol. 1994; 4(5): 1205-1213.

14. Kopple JD; National Kidney Foundation K/DOQI Work Group. The National Kidney Foundation K/DOQI clinical practice guidelines for dietary protein intake for chronic dialysis patients. Am J Kidney Dis. 2001; 38: 68-73.

15. Kidney Disease: Improving Global Outcomes (KDIGO) Blood Pressure Work Group. KDIGO Clinical Practice Guideline for the Management of Blood Pressure in Chronic Kidney Disease. Kidney Int Suppl. 2012; 2: 337-414.

16. Zadrazil J, Strebl P, Krejcí K, Horcicka V, Horák P, Vostálová J, Zdarilová A, Kajabová M, Schneiderka P. Effect of different calcineurin inhibitors on AOPP and TAS after kidney transplantation. Clin Biochem. 2010; 43(6): 559-65. doi: 10.1016/j.clinbiochem.2010.01.003.

17. Witko-Sarsat V, Gausson V, Descamps-Latscha B. Are advanced oxidation protein products potential uremic toxins? Kidney Int Suppl. 2003; 84: 11-14

18. Zhou Q, Wu S, Jiang J, et al. Accumulation of circulating advanced oxidation protein products is an independent risk factor for ischaemic heart disease in maintenance haemodialysis patients. Nephrology (Carlton). 2012; 17(7): 642-9. doi: 10.1111/j.1440-1797.2012.01640.x.

19. Tagore R, Ling LH, Yang H, et al. Natriuretic peptides in chronic kidney disease. Clin J Am Soc Nephrol. 2008; 3(6): 1644-1651.

20. Dziedzic M, Bednarek-Skublewska A, Solski J, Kapka-Skrzypczak L. Plasma and erythrocyte relationship of catecholamines in hemodialysis patients. Ann Agric Environ Med. 2014; 21(3): 562-6. doi: $10.5604 / 12321966.1120602$.

21. Luft FC. Renalase, a catecholamine-metabolizing hormone from the kidney. Cell Metab. 2005; 1(6): 358-360.

22. Li G, Xu J, Wang P, Velazquez H, Li Y, Wu Y, Desir GV. Catecholamines regulate the activity, secretion, and synthesis of renalase. Circulation. 2008; 117(10): 1277-82.

23. Zbroch E, Koc-Zorawska E, Malyszko J, Malyszko J, Mysliwiec M. Circulating levels of renalase, norepinephrine, and dopamine in dialysis patients. Ren Fail. 2013;35(5):673-9. doi: 10.3109/0886022X.2013.778754.

24. Dziedzic M, Ewelina O, Gawel K, Zawadzka M, Bednarek-Skublewska A, Solski J. Plasma levels of catecholamines and asymmetric dimethylarginine levels as predictive values of mortality among hemodialysis patients. Curr Issues Pharm Med Sci. 2014; 27(1): 37-40

25. Malyszko J, Bachorzewska-Gajewska H, Dobrzycki S. Renalase, kidney and cardiovascular disease: are they related or just coincidentally associated? Adv Med Sci. 2015; 60(1): 41-9.

26. Dziedzic M, Petkowicz B, Bednarek-Skublewska A, Solski J, Buczaj A, Choina P. Relationship between renalase and N-terminal pro-B-type natriuretic peptide (NT pro-BNP) in haemodialysis patients. Ann Agric Environ Med. 2014; 21(1): 132-5.
27. Zbroch E, Małyszko J, Małyszko J, Koc-Żórawska E, Myśliwiec M Renalase, kidney function, and markers of endothelial dysfunction in renal transplant recipients. Pol Arch Med Wewn. 2012; 122(1-2): 40-4.

28. Gu R, Lu W, Xie J, Bai J, Xu B. Renalase deficiency in heart failure model of rats--a potential mechanism underlying circulating norepinephrine accumulation. PLoS One 2011; 6(1): e14633.

29. Desir GV, Tang L, Wang P, Li G, Sampaio-Maia B, Quelhas-Santos J, et al. Renalase lowers ambulatory blood pressure by metabolizing circulating adrenaline. J Am Heart Assoc 2012; 1(4): e002634.

30. Quelhas-Santos J, Sampaio-Maia B, Remião F, Serrão P, SoaresSilva I, Desir GV, Pestana M. Assessment of Renalase Activity on Catecholamines Degradation. The Open Hypertension Journal. 2015; 7: 14-18. doi: 10.2174/1876526201507010014.

31. Beaupre BA, Hoag MR, Roman J, Försterling FH, Moran GR. Metabolic function for human renalase: oxidation of isomeric forms of $\beta-N A D(P)$ $\mathrm{H}$ that are inhibitory to primary metabolism. Biochemistry. 2015; 27; 54(3):795-806.

32. Quelhas-Santos J, Serrão MP, Soares-Silva I, Fernandes-Cerqueira C, Simões-Silva L, Pinho MJ, Remião F, Sampaio-Maia B, Desir GV, Pestana M. Renalase regulates peripheral and central dopaminergic activities. Am J Physiol Renal Physiol. 2015; 308(2): F84-91.

33. Malyszko J, Koc-Zorawska E, Zorawski M, Kozminski P, Zbroch E, Rysz J, Banach M, Malyszko JS. Renalase is removed by kidneys and during dialysis - excess related to CKD complications? Curr Vasc Pharmacol. 2015; 13(1): 134-40.

34. Malyszko J, Malyszko JS, Mikhailidis DP, Rysz J, Zorawski M, Banach M. Hypertension and kidney disease: is renalase a new player or an innocent bystander? J Hypertens. 2012; 30(3): 457-62. doi: 10.1097/ HJH.0b013e32834f0bb7.

35. Beaupre BA, Hoag MR, Moran GR. Renalase does not catalyze the oxidation of catecholamines. Arch Biochem Biophys. 2015; 1(579): 626. doi:10.1016/j.abb.2015.05.016.

36. Eikelis N, Hennebry SC, Lambert GW, Schlaich MP. Does renalase degrade catecholamines? Kidney Int. 2011; 79(12): 1380.

37. Wang F, Zhang G, Xing T, Lu Z, Li J, Peng C, Liu G, Wang N. Renalase contributes to the renal protection of delayed ischaemic preconditioning via the regulation of hypoxia-inducible factor-1 $\alpha$. J Cell Mol Med. 2015; 19(6): 1400-9. doi: $10.1111 /$ jcmm.12527.

38. Moran GR. The catalytic function of renalase: A decade of phantoms. Biochim Biophys Acta. 2015; 18: 1570-9639(15)00107-7. doi: 10.1016/j. bbapap.2015.04.010

39. Beaupre BA, Carmichael BR, Hoag MR, Shah DD, Moran GR. Renalase is an alpha-NAD(P)H oxidase/anomerase. J Am Chem Soc. 2013; 135(37): 13980-7.

40. Quelhas-Santos J. et al. Assessment of Renalase Activity on Catecholamines Degradation. Open Hypert J. 2015; 7: 14-18.

41. Xu J, Li G, Wang P, Velazquez H, Yao X, Li Y, Wu Y, Peixoto A, Crowley $\mathrm{S}$, Desir GV. Renalase is a novel, soluble monoamine oxidase that regulates cardiac function and blood pressure. J Clin Invest. 2005; 115(5): 1275-80.

42. Li G, Xu J, Wang P, Velazquez H, Li Y, Wu Y, Desir GV. Catecholamines regulate the activity, secretion, and synthesis of renalase. Circulation. 2008; 117(10): 1277-82.

43. Wang F, Li J, Xing T, Xie Y, Wang N. Serum renalase is related to catecholamine levels and renal function. Clin Exp Nephrol. 2015; 19(1): 92-8.

44. Desir GV, Peixoto AJ Renalase in hypertension and kidney disease. Nephrol Dial Transplant. 2014; 29(1): 22-8.

45. Yin J, Lu Z, Wang F, Jiang Z, Lu L, Miao N, Wang N. Renalase attenuates hypertension, renal injury and cardiac remodelling in rats with subtotal nephrectomy. J Cell Mol Med. 2016; 20(6): 1106-17. 